\title{
Percepção das mulheres acerca do contato precoce e da amamentação em sala de parto
}

\author{
Women's perception concerning the early contact and breastfeeding in childbirth room \\ Opinión de las mujeres referente al contacto precozy lactancia materna en sitio del parto

\begin{abstract}
J uliana Cristina dos Santos Monteiro', Flávia Azevedo Gomes $^{2}$, Ana Márcia Spanó Nakano ${ }^{3}$
\end{abstract}

\begin{abstract}
RESUMO
Objetivo: conhecer e analisar as vivências das mulheres relacionadas ao quarto passo da Iniciativa Hospital Amigo da Criança, em uma maternidade de Ribeirão Preto. Métodos: Foi utilizada a abordagem qualitativa. Os dados foram coletados através de entrevistas semiestruturadas e analisados através da análise de conteúdo, modalidade temática. Resultados: Participaram 23 mulheres que relataram que, mesmo estando em situação inadequada devido ao cansaço e à dor, elas aceitam com resignação e entendem o momento como importante para o bebê. Além disso, receber a criança pela primeira vez causa impacto e surpresa. Considerações finais: A assistência mostra-se limitada aos aspectos práticos do cumprimento do quarto passo, sem considerar os reais sentimentos das mulheres, sendo necessário o desenvolvimento de habilidades de comunicação e empatia pelo profissional de saúde.
\end{abstract}

Descritores: Aleitamento materno; Puerpério; Saúde da mulher

\begin{abstract}
Objective: To describe women's experiences with the fourth step of the Hospital Baby Friendly Initiative. Methods: A qualitative study was undertaken to collect data from 23 women admitted to a maternity hospital, in Ribeirão Preto, Brazil. Data were collected through semistructured interviews and submitted to content analysis. Results: Women stated that earlier contact and breastfeeding the newborn in the delivery room was very important for the newborn. In addition, women stated that receiving the newborn for the first time made them surprised and emotional. Final Considerations: There are several limitations in the application of the fourth step in clinical practice. Health care providers must be sensitive to women's feelings, and must develop empathy and therapeutic communication.
\end{abstract}

Keywords: Breastfeeding; Puerperium; Women's health

\section{RESUMEN}

Objetivo: conocer y analizar las vivencias de las mujeres relacionadas al cuarto paso de la Iniciativa Hospital Amigo da Criança, en una maternidad de Ribeirão Preto. Métodos: Fue utilizado el abordaje cualitativo. Los datos recolectados por medio de entrevistas semiestructuradas fueron analizados a través del análisis de contenido, modalidad temática. Resultados: Participaron 23 mujeres las cuales relataron que, aun estando en situación inadecuada debido al cansancio y al dolor, aceptan con resignación y entienden el momento como importante para el bebé. Además, recibir al niño por primera vez causa impacto y sorpresa. Consideraciones finales: La asistencia se muestra limitada a los aspectos prácticos del cumplimiento del cuarto paso, sin considerar los reales sentimientos de las mujeres, siendo necesario el desarrollo de habilidades de comunicación y empatía del profesional de salud.

Descriptores: Lactancia materna; Puerperio; Salud de la mujer

\footnotetext{
${ }^{1}$ Enfermeira, especialista em Obstetrícia e Neonatologia, mestranda do Programa de Pós-Graduação em Enfermagem em Saúde Pública da Escola de Enfermagem de Ribeirão Preto, da Universidade de São Paulo. USP - Ribeirão Preto (SP), Brasil; Bolsista CNPq.

2 Enfermeira Professora Doutora do Departamento de Enfermagem Materno-Infantil e Saúde Pública da Escola de Enfermagem de Ribeirão Preto da Universidade de São Paulo - USP - Ribeirão Preto (SP), Brasil.

${ }^{3}$ Enfermeira Professora Associada do Departamento de Enfermagem Materno-Infantil e Saúde Pública da Escola de Enfermagem de Ribeirão Preto da Universidade de São Paulo - USP - Ribeirão Preto (SP), Brasil.
} 


\section{INTRODUÇÃO}

As vantagens do leite humano para a saúde e desenvolvimento da criança são comprovadas cientificamente, em termos de proteção contra doenças, como fonte nutricional e pelo fator imunológico que dispõe ${ }^{(1)}$. Em razão disto, o aleitamento materno foi instituído e reafirmado ao longo dos tempos, como estratégia simplificada na atenção primária para a redução da morbidade e mortalidade infantil.

O início dos anos 1990, foi marcado por uma crescente e visível crise de paradigma de amamentação que embasava a política estatal, na medida em que o desmame precoce persiste como importante preocupação na agenda de Saúde Pública, implicando em maior risco de agravo à saúde da criança.

A implantação do Programa Iniciativa Hospital Amigo da Criança (IHAC) no Brasil, a partir de 1992, trouxe um novo fôlego para o incentivo ao aleitamento materno no circuito das políticas públicas ${ }^{(2)}$. Para estimular o aleitamento materno, as instituições que aderem ao movimento da IHAC adotam os chamados "Dez passos para o sucesso do aleitamento materno"(3).

Particularmente considerando o quarto passo - ajudar as mães a iniciar o aleitamento na primeira meia hora após o nascimento, este recomenda o contato pele-a-pele precoce e prolongado no período pós-parto imediato, que deve durar até a primeira mamada ou pelo tempo que a mãe desejar ${ }^{(4)}$. O contato pele-a-pele precoce, evidenciado neste passo, significa colocar o bebê nu em posição prona sobre o peito da mãe imediatamente após o parto ${ }^{(5)}$. Este contato cria um ambiente ótimo para a adaptação do recém-nascido à vida extra-uterina ${ }^{(0)}$, e é considerado como um potencial mecanismo para a promoção do aleitamento materno precoce ${ }^{(7)}$.

O quarto passo da IHAC tem suas bases teóricas sustentadas em evidência científica de benefícios, e auxilia no estabelecimento da sucção precoce que, estimulando a hipófise na produção de prolactina e ocitocina, estimula a produção láctea, e tem efeitos sobre a involução uterina mais rápida e menor sangramento, respectivamente ${ }^{(8)}$. Ainda, favorece o estabelecimento de laços afetivos entre o binômio, mais precisamente nas primeiras duas horas, principalmente se houver contato pele-a-pele. Passadas duas a três horas, o bebê normalmente adormece por longos períodos, o que dificulta o estabelecimento do contato $^{(9)}$.

Diante dessas evidências, as instituições de saúde vêm atuando de forma mais incisiva junto às mulheres, para que estas amamentem seus filhos tão logo tenham parido. Entretanto, temos nos deparado com situações adversas que permeiam a execução do referido passo. Muitas vezes, as mulheres não têm a chance de revelar seus reais desejos e suas condições físicas e emocionais para desenvolver essa função. Considerando que no momento pós-parto imediato, as mulheres manifestam-se cansadas, sonolentas e, ainda, em condições de dor, postura inadequada devido ao posicionamento na mesa de parto, estados de anestesia e recuperação, tais situações podem dificultar o processo de amamentação.

Na perspectiva de mais uma vez não incorrermos no erro de desconsiderar a mulher como sujeito do processo de amamentação, consideramos ser importante compreender como se processam as vivências do contato precoce e de amamentar o filho no momento de seu nascimento, na visão das mulheres/mães. Assim, este estudo teve como objetivos: conhecer e analisar as vivências, por parte das mulheres, em relação ao contato pele-a-pele precoce e amamentação imediatamente após o parto, no contexto de uma instituição Hospital Amigo da Criança; e, depreender os significados atribuídos pelas mulheres às vivências do contato pele-a-pele com o bebê e à amamentação no momento do nascimento e parto; identificar a reação das mulheres ante esta prática, considerando o contexto institucional.

\section{MÉTODOS}

Utilizamos, neste estudo, a abordagem qualitativa, que propõe uma compreensão particular e profunda dos fenômenos sociais em questão ${ }^{(10)}$.

Desenvolvemos nosso estudo com mulheres internadas na Maternidade do Complexo Aeroporto MATER, localizada num bairro da periferia do município de Ribeirão Preto, e que recebeu, em 2002, o título de "Hospital Amigo da Criança" por ter cumprido os "Dez passos para o sucesso do aleitamento materno".

Fizeram parte deste trabalho 23 mulheres com idade entre 18 e 37, assistidas na referida instituição, que tiveram seus filhos colocados em contato pele-a-pele tão logo nasceram, independente de terem ou não amamentado na primeira meia hora após darem à luz, ainda em sala de parto, e que se dispuseram a falar de suas vivências, após receberem as informações referentes à pesquisa e assinarem o Termo de Consentimento Livre e Esclarecido. Com a finalidade de preservar a identidade das mulheres participantes do recorte empírico, foram utilizados nomes fictícios para descrevê-las.

Os dados foram coletados por meio de observação durante o momento do parto e pós-parto imediato, e de entrevista, ambos realizados durante os meses de junho e julho de 2005. As entrevistas foram realizadas utilizandose a modalidade semi-estruturada. Foram utilizadas as seguintes questões norteadoras:

Qual era sua expectativa quanto ao primeiro contato com o seu filho e a amamentação?

Como foi, para você, receber o bebê no colo e amamentar tão logo ele nasceu? 
* Naquele momento, como você descreve sua disposição e a do bebê para segurá-lo no seu peito e para realizar a amamentação?

Todos os depoimentos foram gravados em fitas cassete após a permissão das mulheres entrevistadas, e foram transcritos conforme conveniência da pesquisadora. Todas as entrevistas foram realizadas um dia depois do parto, quando as mulheres estavam em alojamento conjunto na maternidade e já tinham se alimentado e realizado higiene corporal.

Os dados coletados foram analisados, considerandose os registros da observação e por meio da análise de conteúdo, modalidade temática ${ }^{(11)}$.

O projeto de pesquisa foi aprovado pelo Comitê de Ética e Pesquisa da Escola de Enfermagem de Ribeirão Preto - USP, atendendo à determinação da Resolução n. ${ }^{\circ}$ 196/96, sob protocolo no $0497 / 2004$.

\section{RESULTADOS}

O contexto de estudo e a ocorrência do quarto passo da Iniciativa Hospital Amigo da Criança (IHAC)

O ambiente favorável à amamentação inclui procedimentos menos intervencionistas e o favorecimento do contato mãe e filho mais precoce e contínuo ${ }^{(12)}$. No que tange ao tipo de parto, $78.3 \%(\mathrm{n}=18)$ dos partos foram normais, $17.4 \%(n=4)$ foram cesáreas e $4.3 \%(n=1)$ foram fórceps. A utilização do uso de drogas analgésicas para o alívio da dor do trabalho de parto ocorreu em $52.6 \%(\mathrm{n}=10)$ dos partos vaginais $(\mathrm{n}=19)$, sendo que $47.4 \%(n=9)$ das mulheres não utilizaram este recurso.

Considerando os procedimentos realizados com os recém-nascidos, o contato pele-a-pele na primeira meia hora pós-parto ocorreu para $82.6 \%(\mathrm{n}=19)$ dos binômios. Os $17.4 \%(n=4)$ restantes tiveram contato na primeira meia hora, porém a criança foi colocada sobre a camisola da mãe, ou já vestida ou envolvida em lençol. O tempo que o recém-nascido permaneceu sobre o colo da mãe variou entre 2 e 34 minutos, sendo que o tempo médio de permanência foi de 12 minutos. Quanto à primeira amamentação, apenas $52.2 \%(\mathrm{n}=12)$ dos bebês sugaram o seio materno conforme o quarto passo da IHAC. Vale lembrar que, na maternidade, a recepção do recémnascido é realizada dentro da sala de parto, onde o bebê permanece em um berço aquecido que permite que a mãe, ao virar-se para o lado do berço, visualize todos os procedimentos que são realizados com o seu filho.

A participação da mulher na realização do quarto passo da IHAC: manifestando sentimentos de ambivalência

Alguns sentimentos de ambigüidade são verbalizados pelas mulheres no momento do contato precoce com o filho, quando elas estão cansadas, mas referem comentários positivos ao receber o filho no colo pela primeira vez, na instituição.

"Assim, numa parte eu não queria nada com nada. E noutra parte, né, foi bom que eu vi ele, nasceu. Tava bem. Na hora eu tava com dor, tava, mas eu esperava mesmo receber ele, você entendeu? (...) Então, assim, porque o cansaço era demais, a dor, né, porque o primeiro filho, né, não sei, porque eu fui mole, não sei como que, que foi. (...). No momento ali também eu não vou falar assim, ab, eu queria que colocasse no men colo, en ia falar, ah, depois me leva no quarto." (Adriana)

"Tava sentindo muita dor, mas eu fiquei muito feliz, na hora que eu vi ele ali perto de mim, ali. (...) A gente sofre muito, então a gente, eu vi a carinha assim, baixei um pouquinho e já pedi pra tirar, porque eu não agüentava (rs), não. (...) Porque a gente não quer, né? Perto da gente ali, a gente quer que fica ali, mas, é porque a dor é demais, então a gente, prefere pegar depois." (Lúcia)

\section{"Sentindo-se desajeitada"}

A equipe de saúde que assiste ao parto deve criar um ambiente tranqüilo, assim como proporcionar conforto físico e emocional, a fim de facilitar o contato íntimo entre a mãe e o filho, o mais precocemente possível ${ }^{(12)}$. Apesar deste padrão ideal de conforto preconizado e necessário para a realização do quarto passo, nem sempre os profissionais de saúde mostram-se disponíveis para o acolhimento, e as mulheres sentem-se desajeitadas para o primeiro encontro com o filho.

'Pôs a criança, assim, a mãe suada, né, põe a criança em cima. Ai eu já achei errado, nessa parte. Ah, achei muito estranho. Ah, porque en estava suada ali na hora, né. Ah, é muito, ai, eu não gostei, não." (Janete)

"Tem que ficar daquele jeito, né, por causa dos aparelhos". (Marília)

"Estava, não tava judiada muito, não. Ah, porque assim, né, tem mulher que sofre muito, bem mais do que eu, do que eu sofri. Ah, por causa das dores, né, que judia muito! Nossa, isso aí nem dúvida. É, assim, todo mundo sofre, sabe? É coisa da vida, mesmo.Então, sem problema". (Marina)

\section{"Sentir a criança... compensa o sofrimento"}

A ambivalência e o conformismo, que se fazem presentes no padrão idealizado de maternidade demonstrado por estas mulheres, são enfatizados quando elas descrevem suas reações diante de ver e segurar o bebê pela primeira vez.

"Você esquece dor, você esquece tudo naquela hora. Ah, naquele momento você nem vê mais nada, (rs). Depois que você vê que o nenê nasceu, que está tudo bem, você esquece tudo. Você não sente os pontos, você não sente eles te mexer mais, mais nada. É engraçado.(...) eu acho que é aquilo mesmo, é você estar com o bebê. É você sentir ele 
ali. Porque a gente, depois quando você é mãe é, a coisa mais importante é você e o bebê, você não lembra mais de nada." (Leandra)

"Apesar de cansada de tudo que eu passei, as dores, mas pra mim valeu a pena. Que só de eu olhar pra carinha dela, assim, não tem nada assim, que seja mais importante do que o momento. Compensa tudo, as dores, tudo que eu passei”.'(Alessandra)

Imagem do filho recém-nascido: o impacto entre o esperado e o real

O momento de receber o filho que acabou de sair de dentro dela causa impacto e surpresa, pois a realidade deste novo ser é carregada de sensações de estranhamento. A visualização de uma criança envolvida em sangue, líquido amniótico e secreções corporais não é habitual para ela.

"Ah, na hora de impacto assim, pensava que eu levei um susto, né?" (Adriana)

"Eu pensei que tinha acontecido alguma coisa com ela, eu assustei. (...) E, tadinha, ela tava muito judiada, na hora que ela nasceu ela não chorou, e eu jurava que ela já ia sair chorando e não foi assim”.(Cleusa)

"Prontinho - bonitinho / sujinho - esquisitinho"

Receber o bebê ainda envolvido em fluidos corporais como sangue, líquido amniótico e vérnix, mostra-se como não sendo agradável para as participantes. $\mathrm{O}$ nojo e o horror diante do sangue vêm à tona, e o recém-nascido é considerado "sujo" e "esquisito".

"Tem mãe também que não gosta, né, que tem nojo. Não quer".(Aline)

"De repente eu vejo ele em cima de mim todo sujinho (...) Ah, sei lá, todo sujinho, esquisitinho. Aí depois eu já vi que era bebê mesmo, assim, sabe? Sei lá, meia. Ai foi onde que eu comecei chorar e já falar com ele, né? (...) Na hora achei ele assim, esquisitinho, sujinho. Sei lá, dá um, não sei se é medo, não sei te explicar..." (Adriana)

De acordo com os depoimentos, a mulher demonstra o desejo do primeiro contato com o filho já higienizado e vestido.

"Só depois de pronto, bonitinho. É, en imaginava que fosse assim. Com lencolzinho, aventalzinho, mas que ele fosse já preparado, assim".(Rosana)

“(...) naquela época a, eles não deixavam o bebezinho assim, já acompanhado com a mãe, levava pra dar banho, né, agora não leva...” (Alessandra)

\section{"Será que é meu?"}

Deparar-se com um bebê diferente daquele imaginado, idealizado como filho perfeito, lindo, saudável, limpo, leva ao estranhamento e ao desapontamento diante do visualizado por ela. Surge a dúvida quanto ao ser que foi gerado: "será que é meu mesmo?"

"Eu olho assim, sabe, penso assim, será que é meu mesmo? Fico apalpando a barriga, assim, será que já saiu daqui mesmo? (...) Porque você fica pensando, fica meio encucada, será que é meu mesmo?" (Angélica)

"Hora que eu vi, sabe, meu bebê. Até agora eu olho. Será que é gente mesmo? Às vezes ponbo ele do meu lado, assim, fico olhando, será que é meu? (...) Ai depois... achei que era meu mesmo. (...) Parecia que não era gente, sei lá. (rs) Sei lá, foi esquisito." (Adriana)

\section{DISCUSSÃO}

Algumas rotinas hospitalares se constituem em obstáculo para a amamentação, como a administração de medicamentos à mulher, principalmente sedativos e analgésicos ${ }^{(12)}$, o aumento indiscriminado das cesarianas ${ }^{(13)}$, a separação freqüente entre mãe e filho, sendo este último vestido antes de ser levado para a mulher ou encaminhado diretamente ao berçário ${ }^{(14)}$.

A incidência de cesáreas na clientela pesquisada mostrou-se dentro do recomendado pelo Ministério da Saúde que, por meio da Portaria n. ${ }^{\circ}$ 2816/98, institui limites máximos de 30\% de cesárea para o pagamento pelo Sistema Único de Saúde, a fim de reverter a prática abusiva de cesariana no Brasil e contribuir para a redução das taxas de morbidade e mortalidade materna e neonatal ${ }^{(15)}$.

O trabalho de parto, apesar de ser um processo fisiológico e natural, resulta em dor intensa para muitas mulheres ${ }^{(16)}$. Métodos não farmacológicos e farmacológicos podem ajudar a controlar a dor durante o trabalho de parto. A MATER conta com a existência de recursos não farmacológicos para alívio da dor como massagens, hidroterapia e técnicas de respiração. Apesar disto, a maioria das mulheres participantes do estudo utilizaram drogas anestésicas para alívio da dor do trabalho de parto.

O quarto passo da IHAC implica em fazê-lo ainda em sala de parto, já que a dequitação e a atenção ao período de Greemberg podem delongar-se por algum tempo neste local. No entanto, após o parto, a puérpera apresenta-se extenuada pelo esforço muscular dispensado na expulsão; o cansaço exige repouso e o sono é impositivo ${ }^{(17)}$. Em meio ao ambiente hospitalar, onde o contato precoce e o estímulo ao início da amamentação devem ser realizados ainda durante os procedimentos obstétricos que geram o desconforto, a mulher/ parturiente, que agora têm que ser nutriz, relata o cansaço diante desta situação, mas o papel de boa mãe faz a mulher aceitar esta imposição.

O desconforto físico causado pelos procedimentos obstétricos pode interferir no repouso e no relaxamento das mães ${ }^{(18)}$. As mulheres demonstram-se desajeitadas, o 
que significa ainda não ter certas capacidades como conhecimento, prática, postura adequada para a realização do ato de amamentar, o que reforça a idéia de que esta prática é aprendida e não-instintiva ${ }^{(19)}$. Mesmo na presença de dificuldades, as mulheres deste estudo não apresentaram resistência diante do ato de segurar o filho e de amamentar precocemente, aceitando com resignação as atitudes da equipe. Aqui também está presente a ambivalência, pois mesmo "desajeitadas" para segurar e oferecer o peito, elas o aceitam.

Depreendemos aí, o conformismo que permeia as falas das participantes deste estudo, pois mesmo não estando de acordo com as atitudes tomadas pela equipe de saúde, com relação aos seus corpos, mesmo vivenciando uma situação descrita por elas como de sofrimento, existe uma certa passividade que faz com que elas encarem este sofrimento como sendo componente da maternidade.

Pela criança, a mãe suporta tudo, até as temíveis dores do parto; por ela a mãe enfrenta o desconforto de segurála ainda no centro obstétrico, suportando o cansaço, a espera da dequitação, o incômodo dos pontos da sutura perineal. Percebemos aqui o ideal feminino marcado pela construção social e histórica da maternidade romântica, em que as mulheres devem sacrificar-se, doar-se e se restringir em função dos filhos ${ }^{(19)}$. Nesta construção, que começou a ser incorporada a partir do século XVIII, todo sofrimento da mulher é inerente à sua função de mãe e, por isso, deve ser bem tolerado ${ }^{(20)}$. De acordo com os depoimentos, as mulheres, mesmo considerando estarem em uma situação de sofrimento e inadequada, aceitam e entendem o momento como importante para o recémnascido, colocando o seu próprio bem-estar em segundo plano, em detrimento do bem-estar do seu filho, superando o sofrimento por eles.

No que se refere à imagem do filho recém-nascido, a literatura demonstra que o conjunto de metáforas e imagens impresso no modelo ideal de parir e amamentar, traz associações entre maternidade e amamentação, parto e natureza, instinto materno e cuidado com o bebêt(21). $\mathrm{Na}$ instituição hospitalar, o enfoque principal da assistência ao parto e ao recém-nascido está direcionado para a garantia da segurança ao nascimento, sendo uma intervenção para prevenir e/ou tratar doenças, com pouca ênfase no processo normal e fisiológico do nascimento ${ }^{(22)}$. Percebemos que, com a institucionalização/hospitalização do nascimento e parto, as mulheres afastaram-se da compreensão dos fenômenos fisiológicos que permeiam seu corpo. Assim, ao mesmo tempo em que ela carrega a construção cultural do que é ser mulher e mãe, ainda está impregnada com o conceito biologicista de saúde e doença, que medicalizou o nascimento e tornou as situações naturais como não-naturais, o que causa o impacto e a surpresa, ao receber o filho ainda envolvido em sangue e secreções.

Os fluidos corporais são substâncias transmissoras de vida e emoções, mas também têm a denotação de substâncias que transmitem aquilo que pode ser poluído ${ }^{(23)}$. Dependendo da situação, as secreções corporais podem ser codificadas como nojentas e poluidoras; se internalizadas, são consideradas naturais, pois estão devidamente colocadas em seu lugar, e estão controladas pela organização biológica do corpo. Ao ocupar o espaço exterior, as secreções corporais tornam-se perigosas, a natureza está deslocada, poluindo, contaminando o corpo ${ }^{(24)}$. Diante disso, podemos compreender as sensações de nojo e estranhamento das mulheres, ao segurar o recém-nascido nestas condições. Na situação evidenciada, o "sujinho" é entendido como feio, mal acabado. Não é desta maneira que a mulher quer segurar seu filho pela primeira vez. Ela espera vê-lo "prontinho", "bonitinho", característica da criança limpa das secreções corporais.

A reação da mulher pode variar ao ver seu filho pela primeira vez, podendo apresentar explosões de risos, de conversas e choro, até apatia aparente ${ }^{(25)}$. Após o parto, a puérpera apresenta um estado de alteração emocional provisório, onde existe maior fragilidade psíquica, e o mesmo ocorre com o recém-nascido; a relação inicial entre este binômio é ainda pouco estruturada, intensamente emocional e mobilizadora(26). Neste estudo, depreendemos que a imagem do filho recém-nascido gera sentimentos inesperados para a mulher que se torna mãe. O recém-nascido deixa de ser idealizado e passa a ser vivenciado como um ser real e diferente ${ }^{(26)}$; as características com as quais o seu filho se apresenta são incomuns para a mulher.

\section{CONSIDERAÇÕES FINAIS}

Analisar o significado do contato precoce com o filho recém-nascido, para a mulher nos permitiu visualizar com maior abrangência, sua disponibilidade para este momento, e entender a sua lógica. As mulheres sentem-se sozinhas, sem apoio para tomarem suas decisões individuais sobre seu corpo e os profissionais de saúde, numa atitude paternalista e intervencionista, mais uma vez se interpõem entre mães e filhos.

A partir dos discursos das mulheres, percebemos que é necessário colocar no centro das discussões suas vivências referentes aos momentos iniciais de relação com o filho recém-nascido e de adaptação à função de nutriz. Compreender o significado do contato precoce e da amamentação, ainda em sala de parto, implica em respeitar o desejo, a cultura e o suporte social de cada mulher que é recebida para a resolução da gestação e assistência ao puerpério imediato.

A equipe de enfermagem exerce papel importante 
nesta transição entre mulher/mãe/nutriz, que se dá no centro obstétrico e na maternidade. Como promotora das ações e passos da IHAC, esta equipe orienta e auxilia a mulher durante as práticas institucionalizadas e, no que tange ao quarto passo, é o profissional de enfermagem que está junto ao binômio, para garantir que seja realizado. Portanto, para que o quarto passo tenha seus objetivos alcançados e possa promover o vínculo entre mãe e filho, incentivando o aleitamento materno, faz-se necessário atenção à mulher durante este momento, informando-a e auxiliando-a no contato precoce. Torna-se evidente que a mulher deve fazer parte deste momento, tendo poder de decisão sobre o contato precoce e a primeira amamentação, e sendo sujeito das suas ações, não apenas recebendo e aceitando o quarto passo da IHAC, sem refletir sobre ele, anteriormente. Entendemos que a mudança de atitude do profissional, com a integração e valorização do binômio mãe e filho, pode facilitar a operacionalização do quarto passo da IHAC, de modo que este seja realizado não apenas de forma mecanicista e fragmentada, mas com respeito e acolhimento.

\section{REFERÊNCIAS}

1. Giugliani ERJ. Evolução Histórica da Amamentação. In: Santos Junior LA. A mama no ciclo gravídico-puerperal. São Paulo: Atheneu; 2000.

2. Souza LMBM. Promoção, proteção e apoio. Apoio? Representações sociais em aleitamento materno [tese]. Rio de Janeiro: Instituto Fernandes Figueira da Fundação Oswaldo Cruz; 1996.

3. Organização Mundial da Saúde. Organização Pan-Americana da Saúde. Ministério da Saúde (Brasil). Evidências científicas dos dez passos para o sucesso no aleitamento materno. Brasília: OPAS; 2001.

4. World Health Organization; United Nations Children's Fund. Implementing the tem steps to successful breastfeeding. Geneva, Switzerland: WHO; 1998.

5. Alberts JR. Learning as adaptation of the infant. Acta Paediatr Suppl. 1994; 397: 77-85.

6. Mikiel-Kostyra K, Mazur J, Boltruszko I. Effect of early skin-to-skin contact after delivery on duration of breastfeeding: a prospective cohort study. Acta Paediatr. 2002; 91(12): 1301-6.

7. Righard L, Alade MO. Effect of delivery room routines on success of first breast-feed. Lancet. 1990; 336(8723): 1105-7.

8. Mattar R, Abrão ACV. Aleitamento materno: manejo clínico. In: Camano L, Souza E, Sass N, Mattar R. Guias de medicina ambulatorial e hospitalar. UNIFESP - Escola Paulista de Medicina - Obstetrícia. São Paulo: Manole; 2003.

9. Fundação Das Nações Unidas Para Infância. Manejo e promoção do aleitamento materno. New York: OMS/ OPAS/UNICEF; 1993.

10. Minayo MCS. O desafio do conhecimento: pesquisa qualitativa em saúde. 5a ed. São Paulo: Hucitec: ABRASCO; 1998.

11. Bardin L. Análise de conteúdo. Lisboa: Edições 70; 1977.

12. Ministério da Saúde. Secretaria de Políticas de Saúde. Área Técnica de Saúde da Mulher. Parto, aborto e puerpério: assistência humanizada à mulher. Brasília: Ministério da Saúde; 2001.

13. Rowe-Murray HJ, Fisher JR. Baby friendly hospital practices: cesarean section is a persistent barrier to early initiation of breastfeeding. Birth. 2002; 29(2): 124-31.

14. Carfoot S, Williamson PR, Dickson R. A systematic review of randomised controlled trials evaluating the effect of mother/baby skin-to-skin care on successful breast feeding. Midwifery. 2003; 19(2): 148-55.

15. Oliveira SMJV, Gonzalez Riesco ML, Rosas Miya CF, Vidotto P. Tipo de parto: expectativas das mulheres. Rev Latinoam Enfermagem. 2002; 10(5): 667-74.

16. Lowe NK. The nature of labor pain. Am J Obstet Gynecol. 2002; 186 (5 Suppl Nature): S16-24. Review.

17. Neme B. Obstetrícia básica. 2a ed. São Paulo: Sarvier; 2000.

18. Lowdermilk DL, Perry SE, Bobak IM. O cuidado em enfermagem materna. 5a ed. Porto Alegre: Artmed; 2002.

19. Nakano AMS. As vivências da amamentação para um grupo de mulheres: nos limites de ser "o corpo para o filho" e de ser "o corpo para si" [tese ]. Ribeirão Preto: Escola de Enfermagem de Ribeirão Preto da Universidade de São Paulo; 2004.

20. Badinter E. Um amor conquistado: o mito do amor materno. 3a ed. Rio de Janeiro: Nova Fronteira; 1985.

21. Tornquist CS. Armadilhas da nova era: natureza e maternidade no ideário da humanização do parto. Estud Fem. 2002; 10(2): 483-92.

22. Chalmers B. How often must we ask for sensitive care before we get it? Birth. 2002; 29(2): 79-82.

23. Leal OF. Sangue, fertilidade e práticas contraceptivas. In: Alves PC, Minayo MCS, organizadores. Saúde e doença: um olhar antropológico. Rio de Janeiro: Fiocruz; 1998. p.127-40.

24. Rodrigues JC. Tabu do corpo. 4a ed. Rio de Janeiro: Dois Pontos; 1986.

25. Piotrowski KA. Cuidado de enfermagem durante o parto e o nascimento. In: Lowdermilk DL, Perry SE, Bobak IM. O cuidado em enfermagem materna. 5a ed. Porto Alegre: Artmed; 2002. p.356-414.

26. Sarmento R, Setúbal MSV. Abordagem psicológica em obstetrícia: aspectos emocionais na gravidez, parto e puerpério. Rev Ciências Médicas. 2003; 12(3): 261-8. 